\title{
Regresi Logistik Ordinal untuk Mengetahui Faktor-Faktor yang Mempengaruhi Motivasi Menabung Mahasiswa
}

(Studi Kasus Mahasiswa PAI Universitas KH. A Wahab Hasbullah Tambakberas)

\author{
Dian Kusuma Wardani ${ }^{(1)}$, Khusnul Khotimah ${ }^{(2)}$ \\ Program Studi Pendidikan Agama Islam, Fakultas Agama Islam ${ }^{(1,2)}$ \\ Universitas KH. A. Wahab Hasbullah \\ Jl. Garuda No. 9 Tambakrejo Jombang, 61415 \\ e-mail: dianwardani@unwaha.ac.id dan khusnulkhotimah@unwaha.ac.id
}

\begin{abstract}
ABSTRAK
Analisis jalur (path analysis) dikembangkan oleh Sewall Wright pada tahun 1934 yang bertujuan untuk menerangkan akibat langsung dan tidak langsung dari seperangkat variabel penyebab (variabel eksogen) terhadap seperangkat variabel akibat (variabel endogen). Analisis jalur dalam penelitian ini digunakan sebagai konseptul untuk memperkuat teoritis, sedangkan metode analisis menggunakan regresi logistik ordinal. Data primer digunakan dalam penelitian ini. Jumlah populasi sebanyak 421 mahasiswa program studi Pendidikan Agama Islam Universitas KH A Wahab Hasbullah. Teknik sampling yang digunakan yaitu simple random sampling, dan dari hasil perhitungan didapatkan 75 sampel yang diambil dari populasi Metode analisis yang digunakan pada penelitian ini menggunakan analisis jalur (path analysis). Tujuan penelitian ini untuk mengetahui hubungan struktural antara variabel eksogen (motivasi orang tua, motivasi dosen, kebutuhan pribadi mahasiswa dan program menabung dikampus) terhadap variabel endogen (pemahaman mahasiswa uang dan menabung dan motivasi menabung). Hasil penelitian menunjukkan bahwa variabel $\mathrm{Y}_{2}$ (minat mahasiswa menabung) mendapat pengaruh langsung maupun tidak langsung dari variabel $\mathrm{X}_{1}$ (orang tua) dan $\mathrm{X}_{2}$ (dosen). Sedangkan variabel $\mathrm{X}_{3}$ (kebutuhan mahasiswa) dan $\mathrm{X}_{4}$ (program menabung kampus) hanya memberikan pengaruh langsung.
\end{abstract}

Kata kunci : Endogen, Eksogen, Sampling, Rgresi Logistik Ordinal.

\section{ABSTRACT}

Path Analysis was developed by Sewall Wright in 1934 which aims to explain the direct and indirect effects of a set of causal variables (exogenous variables) on a set of effect variables (endogenous variables). Primary data is used in this study. The population is 421 students of the Islamic Religious Education study program at KH A Wahab Hasbullah University. The sampling technique used is simple random sampling, and from the calculation results obtained 75 samples taken from the population. The analysis method used in this study uses path analysis. The purpose of this study was to determine the structural relationship between exogenous variables (parent motivation, lecturer motivation, student's personal needs and savings program in campus) to endogenous variables (student understanding of money and saving and saving motivation). The results showed that the $Y_{2}$ variable (students' interest in saving) had a direct or indirect influence from the variables $X_{1}$ (parents) and $X_{2}$ (lecturers). Whereas the variables $X_{3}$ (student university needs) and $X_{4}$ (saving program in campus) have a direct effect.

\section{Keywords : Endogenous, Exogenous, Sampling, Ordinal Logistic Regression.}

\section{PENDAHULUAN}

Menabung adalah salah satu pilar penting dalam pengelolaan keuangan. Kebiasaan menabung akan mengajarkan anak mengelola keuangan secara pribadi. Anak bisa menentukan sendiri seberapa besar dari uang yang diterima akan disisihkan untuk ditabung dan seberapa besar yang akan dibelanjakan. Menabung membuat anak memiliki perencanaan, akan digunakan untuk apa hasil tabungan. Belajar menabung membantu anak belajar disiplin. Anak akan memiliki kebanggaan jika bisa mengumpulkan uang yang cukup banyak dalam waktu yang lama. Anak akan bangga jika bisa membeli sesuatu menggunakan uang hasil tabungan sendiri.

Kesadaran anak dalam menabung sangat dipengaruhi oleh lingkungan sekitar, khususnya orang tua. Pemahaman yang tepat tentang uang, 
tujuan dan manfaat menabung yang ditanamkan oleh orang tua dirumah akan membentuk pribadi anak yang sadar akan fungsi uang dan manfaat menabung. Peran dosen di kampus tidak kalah penting dalam membentuk kesadaran menabung pada anak sejak dini. Kesadaran anak menabung dirasa penting karena sejalan dengan terbentuknya jiwa entrepreunership.

Penelitian terdahulu yang pernah dilakukan Wahana Arwansa (2014) menyatakan bahwa faktor-faktor yang mempengaruhi perilaku mahasiswa dalam menabung menggunakan model regresi logistik menunjukkan bahwa variabel literasi keuangan, variabel pengendalian diri, variabel motif menabung, variabel pendapatan berpengaruh positif dan signifikan terhadap probabilitas menabung. Studi kasus penelitian ini yaitu mahasiswa S1 FEB Universitas Diponegoro Temabalang. Faktor-faktor yang mempengaruhi motivasi menabung mahasiswa di SMP Negeri 1 Kampar pada tahun 2012 yaitu minat menabung, sikap menabung dan harapan dalam menabung (Amelia Fitria, 2012).

Penelitian mengenai analisis jalur pernah dilakukan oleh Tanzia, Ike dan Herdiana (2009) dengan judul Analisis Jalur Faktor-Faktor Yang Mempengaruhi Ketahanan Pangan Rumah Tangga di Kabupaten Lebak Provinsi Banten. Kesimpulan dari hasil penelitian tersebut adalah tidak terdapat hubungan yang signifikan antara pendidikan kepala rumah tangga, pendidikan irt, pengetahuan gizi ibu dan dukungan sosial dengan ketahanan pangan rumah tangga. Terdapat hubungan yang signifikan antara jumlah anggota rumah tangga dan pengeluaran per kapita dengan ketahanan pangan rumah tangga. Pengaruh langsung terbesar terhadap ketahanan pangan rumah tangga adalah pengeluaran rumah tangga. Jalur tidak langsung yang paling berpengaruh terhadap ketahanan pangan rumah tangga adalah dimulai dari penurunan jumlah anggota rumah tangga pengeluaran per kapita ketahanan pangan rumah tangga.

Tujuan penelitian untuk mengetahui hubungan struktural antara variabel eksogen (motivasi orang tua, motivasi dosen, kebutuhan pribadi mahasiswa dan program menabung dikampus) terhadap variabel endogen (pemahaman mahasiswa uang dan menabung dan motivasi menabung).

\section{KAJIAN LITERATURE}

Analisis jalur merupakan metode untuk mempelajari pengaruh langsung, pengaruh tidak langsung, pengaruh tak teranalisis dan pengaruh semu diantara variabel bebas dan variabel respon.
Pengaruh langsung yaitu pengaruh suatu variabel bebas terhadap variabel respon secara langsung tanpa dipengaruhi oleh variabel bebas lainnya. Sedangkan pengaruh tidak langsung adalah pengaruh variabel bebas terhadap variabel respon yang masih dipengaruhi oleh variabel bebas lainnya. Terdapat dua jenis variabel dalam analisis jalur yaitu variabel endogen dan variabel eksogen. Variabel eksogen merupakan variabel yang hanya dapat mempengaruhi, sedangkan variabel endogen merupakan variabel yang hanya dipengaruhi atau dipengaruhi dan mempengaruhi variabel lain. Metode ini merupakan salah satu metode yang digunakan untuk menjelaskan sistem dengan variabel-variabel yang saling berhubungan. Analisis jalur menghitung kekuatan hubungan dengan hanya menggunakan matriks korelasi atau koragam sebagai input (Hair, 1995).

Regresi logistik ordinal merupakan salah satu metode statistika untuk menganalisis variabel respon yang mempunyai skala ordinal yang terdiri atas tiga kategori atau lebih. Model yang dapat dipakai untuk regresi logistik ordinal adalah model logit. Model tersebut adalah cumulative logit models. Pada model logit ini sifat ordinal dari respon $\mathrm{Y}$ dituangkan dalam peluang kumulatif sehingga cumulative logit models merupakan model yang didapatkan dengan membandingkan peluanga kumulatif yaitu peluang kurang dari atau sama dengan kategori respon ke-j pada $\mathrm{p}$ variabel bebas yang dinyatakan dalam vector $\mathbf{X}, \mathrm{P}(\mathrm{Y} \leq \mathrm{j} \mid \mathbf{X})$, dengan peluang lebih besar dari kategori respon kej, $\mathrm{P}(\mathrm{Y}>\mathrm{j} \mid \mathbf{X})$ (Hosmer dan Lemeshow, 2000).

Peluang kumulatif $\mathrm{P}(\mathrm{Y} \leq \mathrm{j} \mid \mathrm{X})$ didefinisikan sebagai berikut (Agresti, 1990):

$$
P(Y \leq j \mid \mathbf{X})=\frac{\exp \left(\theta_{j}+\sum_{k=1}^{p} \beta_{k} X_{k}\right)}{1+\exp \left(\theta_{j}+\sum_{k=1}^{p} \beta_{k} X_{k}\right)}
$$

di mana $\mathrm{j}=1,2, . . \mathrm{J}$ dan $\mathrm{J}=$ kategori respon

Menabung diartikan sebagai kegiatan menyisihkan uang yang dimiliki untuk disimpan di celengan maupun bank. Kegiatan menabung dilakukan secara bertahap. Menabung adalah kegiatan ekonomi yang kita lakukan sebagai langkah antisipasi kondisi kita di masa depan. Dengan menabung, maka kita dapat mengumpulkan beberapa rupiah uang kita dan dipersiapkan untuk kebutuhan masa depan yang lebih baik. Tabungan adalah menyimpan sebagian pendapatan seseorang yang tidak dibelanjakan sebagai cadangan yang dapat digunakan sewaktuwaktu bila diperlukan (Hasibuan, 2008). 
Menabung merupakan aktifitas menyimpan sebagian pendapatan yang digunakan untuk memenuhi kebutuhan penting dan mendadak untuk masa yang akan datang. Pengeluaran seseorang untuk konsumsi dan tabungan dipengaruhi oleh pendapatan. Fungsi dari tabungan adalah suatu kurva yang menggambarkan sifat hubungan di antara tingkat tabungan rumah tangga dalam perekonomian dengan pendapatan nasional (pendapatan disposibel) perekonomian (Ritonga, 2006).

Minat adalah kecenderungan yang menetap untuk memperhatikan dan mengenang beberapa aktivitas. Seseorang yang berminat terhadap suatu aktivitas akan memperhatikan itu secara konsisten dengan rasa senang. Dengan kata lain, minat adalah suatu rasa suka dan keterikatan pada suatu hal atau aktivitas tanpa ada yang menyuruh (Djamarah, 2002). Pengertian lain tentang minat adalah suatu rasa lebih suka dan rasa keterikatan pada suatu hal atau aktivitas, tanpa ada yang menyuruh. Minat pada dasarnya adalah penerimaan akan suatu hubungan antara diri sendiri dengan sesuatu diluar diri. Semakin kuat atau dekat hubungan tersebut semakin besar minatnya (Slameto, 2004).

Motivasi menabung memegang peranan penting dalam diri mahasiswa karena dapat menumbuhkan gairah, merasa senang, dan semangat untuk menabung. Mahasiswa yang mempunyai motivasi menabung yang kuat akan melakukan aktivitas-aktivitas menabung, karena motivasi menabung ini adalah dorongan atau daya gerak yang tumbuh di dalam diri mahasiswa untuk melakukan aktivitas menabung tersebut.

Uji validitas digunakan untuk mengukur sah atau valid tidaknya suatu kuesioner. Suatu kuesioner dikatakan valid jika pertanyaan pada kuesioner mampu untuk mengungkapkan sesuatu yang akan diukur oleh kuesioner tersebut (Ghazali, 2011). Sunyoto (2011) menyebutkan bahwa uji validitas dapat dilakukan dengan menghitung korelasi antara skor masing-masing butir pertanyaan dengan total skor.

Reliabilitas sebenarnya adalah alat untuk mengukur suatu kuesioner yang merupakan indikator dari variabel atau konstruk. Suatu kuesioner dikatakan reliabel atau handal jika jawaban seseorang terhadap pernyataan adalah konsisten dari waktu ke waktu (Ghazali, 2011). Dalam penelitian ini pengukuran reliabilitas butir pertanyaan dengan cara one shoot atau pengukuran sekali saja. Menurut Sunyoto (2011) suatu konstruk atau variabel diakatakan reliabel apabila memberikan nilai Cronbach Alpha lebih dari 0,60.

\section{METODE PENELITIAN}

Penelitian ini dilakukan pada mahasiswa program studi Pendidikan Agama Islam Universitas KH. A Wahab Hasbullah Tambakberas Jombang. Data yang digunakan dalam penelitian ini merupakan data primer yaitu data hasil kuesioner. Jumlah anggota populasi didapatkan dari Tata Usaha kampus yaitu angkatan aktif sebesar 421 mahasiswa. Teknik sampling yang digunakan simple random sampling. Variabel dalam penelitian ini dapat diidentifikasi sebagai variabel eksogen dan variabel endogen. Variabel eksogen dalam penelitian ini antara lain orang tua $\left(\mathrm{X}_{1}\right)$, Dosen $\left(\mathrm{X}_{2}\right)$, kebutuhan mahasiswa $\left(\mathrm{X}_{3}\right)$, dan program menabung kampus $\left(\mathrm{X}_{4}\right)$. Sedangkan variabel endogen adalah pemahaman mahasiswa mengenai uang dan menabung $\left(\mathrm{Y}_{1}\right)$ dan minat mahasiswa menabung $\left(\mathrm{Y}_{2}\right)$.

Terdapat 4 model yang akan dianalsisi dalam penelitian untuk mengetahui faktor menabung mahasiswa. Model pertama adalah pemahaman siswa sebagai respon dan faktor orang tua dan dosen sebagai prediktor. Model kedua dimana minat menabung sebagai respon dan prediktor yang sama dengan model pertama. Model ketiga kebutuhan mahasiswa dan program menabung menjadi faktor dengan respon adalah minat menabung mahasiswa. Model keempat untuk mengetahui kebenaran bahwa pengetahuan mahasiswa mengenai menabung menjadi faktor yang mempengaruhi minat mahasiswa menabung. Langkah-langkah analisis sebagai berikut:

1. Uji validitas dan reliabiltas untuk kuisioner

2. Merancang model berdasarkan konsep dan teori

3. Menggambar diagram jalur berdasarkan langkah kedua

4. Menduga model regresi logistik secara simultan untuk setiap variabel endogen dengan metode Maximum Likelihood Estimation (MLE). Metode iterasi yang digunakan adalah Newton Raphson

5. Uji kesesuian model menggunakan statistik uji yang terdiri dari Pearson dan Deviance. Kemudian menghitung Koefisien Determinasi $\left(\mathrm{R}^{2}\right)$. Untuk ketepatan klasifikasi digunakan Persen Ketepatan Klasifikasi (PKK) dengan menggunakan program SPSS.

6. Menghitung efek langsung dan tidak langsung variabel eksogen menggunakan Excel. Interpretasi efek langsung dan tidak langsung dengan menggunakan odds ratio.

Tabel 1 menjelaskan tentang variabel eksogen dan variabel endogen berserta kategori dan skala pengukurannya. 
Tabel 1. Keterangan Variabel

\begin{tabular}{|c|c|c|}
\hline Variabel & Kategori & Sifat \\
\hline$X_{1}=$ Orang tua & $\begin{array}{l}5=\text { Sangat setuju } \\
4=\text { Setuju } \\
3=\text { Kurang Setuju } \\
2=\text { Tidak Setuju } \\
1=\text { Sangat tidak setuju }\end{array}$ & Ordinal \\
\hline $\mathrm{X}_{2}=$ Guru & $\begin{array}{l}5=\text { Sangat setuju } \\
4=\text { Setuju } \\
3=\text { Kurang Setuju } \\
2=\text { Tidak Setuju } \\
1=\text { Sangat tidak setuju }\end{array}$ & Ordinal \\
\hline $\mathrm{X}_{3}=$ Program Menabung sekolah & $\begin{array}{l}5=\text { Sangat setuju } \\
4=\text { Setuju } \\
3=\text { Kurang Setuju } \\
2=\text { Tidak Setuju } \\
1=\text { Sangat tidak setuju }\end{array}$ & Ordinal \\
\hline$X_{4}=$ Kebutuhan siswa & $\begin{array}{l}5=\text { Sangat setuju } \\
4=\text { Setuju } \\
3=\text { Kurang Setuju } \\
2=\text { Tidak Setuju } \\
1=\text { Sangat tidak setuju }\end{array}$ & Ordinal \\
\hline $\mathrm{Y}_{1}=$ Pemahaman siswa & $\begin{array}{l}5=\text { Sangat mengerti } \\
4=\text { Mengerti } \\
3=\text { Kurang Mengerti } \\
2=\text { Tidak mengerti } \\
1=\text { Sangat tidak mengerti }\end{array}$ & Ordinal \\
\hline $\mathrm{Y}_{2}=$ Minat siswa menabung & $\begin{array}{l}5=\text { Sangat bersemangat } \\
4=\text { Semangat } \\
3=\text { Kurang Semangat } \\
2=\text { Tidak Bersemangat } \\
1=\text { Sangat tidak bersemangat }\end{array}$ & Ordinal \\
\hline
\end{tabular}

\section{HASIL DAN PEMBAHASAN}

\subsection{Uji Validitas Instrumen Penelitian}

Instrumen Penelitian perlu dilakukan pengujian validitas untuk mengetahui kevalidan setiap butir pertanyan. Pada Tabel 2 didapatkan bahwa nilai $p$-value untuk setiap butir pertanyaan nilainya kurang dari $\alpha(0.05)$ maka dapat disimpulkan bahwa butir pertanyaan yang ada sudah valid atau dapat dikatakan bahwa pengujian validitas telah terpenuhi

Tabel 2. Hasil Pengujian Validitas Instrumen Penelitian

\begin{tabular}{|c|c|c|c|c|c|c|}
\hline Variabel & $\mathbf{X}_{1}$ & $\mathbf{X}_{2}$ & $\mathbf{X}_{3}$ & $\mathbf{X}_{4}$ & $\mathbf{Y}_{1}$ & $\mathbf{Y}_{2}$ \\
\hline \multirow{2}{*}{$\mathrm{X}_{1}$} & 1 & $0.238 * *$ & $0.340 * *$ & $0.416^{* * *}$ & $0.433 * *$ & $0.256 * *$ \\
\hline & & 0.000 & 0.000 & 0.000 & 0.000 & 0.000 \\
\hline \multirow{2}{*}{$X_{2}$} & & 1 & $0.196 * *$ & $0.299 * *$ & $0.352 * *$ & $0.160 * *$ \\
\hline & & & 0.001 & 0.000 & 0.000 & 0.008 \\
\hline \multirow{2}{*}{$\mathrm{X}_{3}$} & & & 1 & $0.202 * *$ & $0.152 *$ & $0.188 * *$ \\
\hline & & & & 0.001 & 0.012 & 0.002 \\
\hline \multirow{2}{*}{$\mathrm{X}_{4}$} & & & & 1 & $0.478 * *$ & $0.323 * *$ \\
\hline & & & & & 0.000 & 0.000 \\
\hline $\mathrm{Y}_{1}$ & & & & & 1 & $0.192 * *$ \\
\hline $\mathrm{Y}_{2}$ & & & & & & 1 \\
\hline
\end{tabular}




\subsection{Uji Reliabilitas Intrumen Penelitian}

Hasil uji reliabilitas pada keseluruhan instrument dapat dilihat pada Tabel 3 berikut

Tabel 3. Hasil Uji Reliabilitas Instrumen Penelitian

\begin{tabular}{ccc}
\hline $\begin{array}{c}\text { Cronbach's } \\
\text { Alpha }\end{array}$ & $\begin{array}{c}\text { Cronbach's } \\
\text { Alpha Based on } \\
\text { Standardized } \\
\text { Items }\end{array}$ & N of Items \\
\hline 0.692 & 0.702 & 6 \\
\hline
\end{tabular}

Tabel 3 didapatkan bahwa nilai Cronbach's Alpha sebesar 0.692. Dengan nilai Cronbach's Alpha $(0.692)>0.6$, maka dapat disimpulkan bahwa butir pertanyaan yang ada sudah reliabel atau dapat dikatakan bahwa pengujian reliabilitas telah dipenuhi.

\subsection{Model Duga Regresi Logistik Ordinal}

Terdapat enam macam hubungan yang dianalisis yaitu hubungan antara variabel $X_{1}$ dan $X_{2}$ yang mempengaruhi $Y_{1}$, hubungan antara variabel $\mathrm{X}_{3}$ yang mempengaruhi $\mathrm{Y}_{2}$, hubungan antara variabel $X_{4}$ terhadap $Y_{2}$, hubungan antara variabel $Y_{1}$ terhadap $Y_{2}$, hubungan antara variabel $X_{1}$ terhadap $\mathrm{Y}_{2}$ dan hubungan antara variabel $\mathrm{X}_{2}$ terhadap $\mathrm{Y}_{2}$. Keempat hubungan yang dianalisis dapat dijelaskan dengan Gambar 1 berikut.
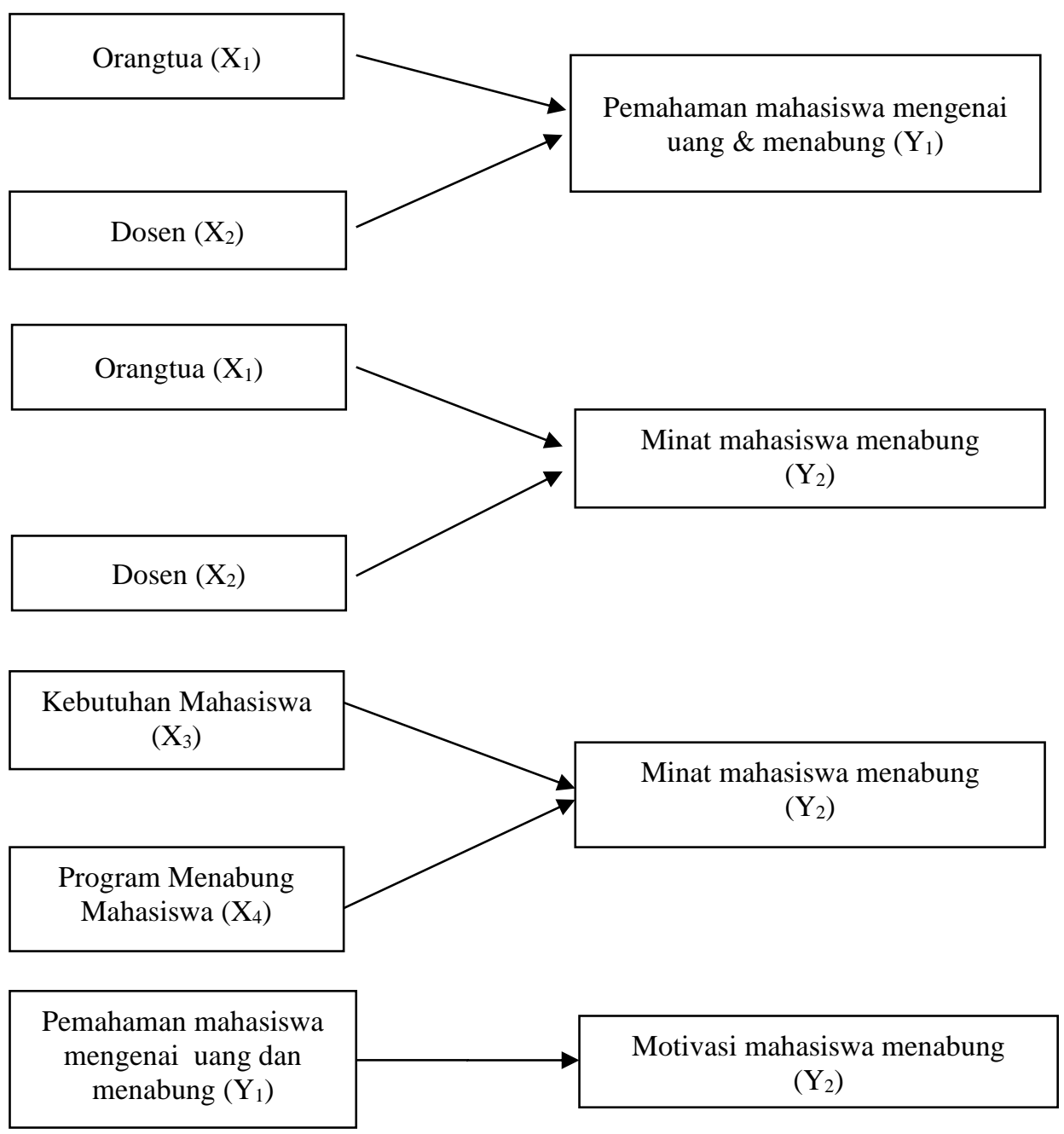

Gambar 1. (1) Hubungan 1; (2) Hubungan 2; (3) Hubungan 3 dan (4) Hubungan 4

Dari hasil pendugaan parameter model regresi logistik ordinal untuk setiap hubungan tersebut maka dapat dibuat model logit regresi logistik ordinal sebagai berikut :

1. Model Hubungan Struktural 1 dimana terdapat tiga model 


$$
\begin{aligned}
& \pi_{y 1}(x)=\frac{\exp \left(5.697+1.465 x_{1(2)}+3.305 x_{1(3)}+1.735 x_{1(4)}+1.992 x_{2(2)}+0.651 x_{2(3)}+1.296 x_{2(4)}\right)}{1+\exp \left(5.697+1.465 x_{1(2)}+3.305 x_{1(3)}+1.735 x_{1(4)}+1.992 x_{2(2)}+0.651 x_{2(3)}+1.296 x_{2(4)}\right)} \\
& \pi_{y 1}(x)=\frac{\exp \left(4.825+1.465 x_{1(2)}+3.305 x_{1(3)}+1.735 x_{1(4)}+1.992 x_{2(2)}+0.651 x_{2(3)}+1.296 x_{2(4)}\right)}{1+\exp \left(4.825+1.465 x_{1(2)}+3.305 x_{1(3)}+1.735 x_{1(4)}+1.992 x_{2(2)}+0.651 x_{2(3)}+1.296 x_{2(4)}\right)} \\
& \pi_{y 1}(x)=\frac{\exp \left(1.982+1.465 x_{1(2)}+3.305 x_{1(3)}+1.735 x_{1(4)}+1.992 x_{2(2)}+0.651 x_{2(3)}+1.296 x_{2(4)}\right)}{1+\exp \left(1.982+1.465 x_{1(2)}+3.305 x_{1(3)}+1.735 x_{1(4)}+1.992 x_{2(2)}+0.651 x_{2(3)}+1.296 x_{2(4)}\right)}
\end{aligned}
$$

2. Model Hubungan Struktural 2 terdapat dua model regresi logistik

$$
\begin{aligned}
& \pi_{y 2}(x)=\frac{\exp \left(5.404+2.697 x_{1(2)}+3.581 x_{1(3)}+0.639 x_{1(4)}+0.666 x_{2(2)}+1.002 x_{2(3)}+0.594 x_{2(4)}\right)}{1+\exp \left(5.404+2.697 x_{1(2)}+3.581 x_{1(3)}+0.639 x_{1(4)}+0.666 x_{2(2)}+1.002 x_{2(3)}+0.594 x_{2(4)}\right)} \\
& \pi_{y 2}(x)=\frac{\exp \left(0.620+2.697 x_{1(2)}+3.581 x_{1(3)}+0.639 x_{1(4)}+0.666 x_{2(2)}+1.002 x_{2(3)}+0.594 x_{2(4)}\right)}{1+\exp \left(0.620+2.697 x_{1(2)}+3.581 x_{1(3)}+0.639 x_{1(4)}+0.666 x_{2(2)}+1.002 x_{2(3)}+0.594 x_{2(4)}\right)}
\end{aligned}
$$

3. Model Hubungan Struktural 3

$$
\begin{aligned}
& \pi_{y 2}(x)=\frac{\exp \left(5.888+1.626 x_{3(2)}+0.761 x_{3(3)}+0.248 x_{3(4)}+3.242 x_{4(1)}+24.948 x_{4(2)}+1.921 x_{4(3)}+0.698 x_{4(4)}\right)}{1+\exp \left(5.888+1.626 x_{3(2)}+0.761 x_{3(3)}+0.248 x_{3(4)}+3.242 x_{4(1)}+24.948 x_{4(2)}+1.921 x_{4(3)}+0.698 x_{4(4)}\right)} \\
& \pi_{y 2}(x)=\frac{\exp \left(0.596+1.626 x_{3(2)}+0.761 x_{3(3)}+0.248 x_{3(4)}+3.242 x_{4(1)}+24.948 x_{4(2)}+1.921 x_{4(3)}+0.698 x_{4(4)}\right)}{1+\exp \left(0.596+1.626 x_{3(2)}+0.761 x_{3(3)}+0.248 x_{3(4)}+3.242 x_{4(1)}+24.948 x_{4(2)}+1.921 x_{4(3)}+0.698 x_{4(4)}\right)}
\end{aligned}
$$

4. Model Hubungan Struktural 4

$$
\begin{aligned}
& \pi_{y 2}(x)=\frac{\exp \left(4.626+1.236 x_{5(2)}+0.888 x_{5(3)}+0.775 x_{5(4)}\right)}{1+\exp \left(4.626+1.236 x_{5(2)}+0.888 x_{5(3)}+0.775 x_{5(4)}\right)} \\
& \pi_{y 2}(x)=\frac{\exp \left(0.264+1.236 x_{5(2)}+0.888 x_{5(3)}+0.775 x_{5(4)}\right)}{1+\exp \left(0.264+1.236 x_{5(2)}+0.888 x_{5(3)}+0.775 x_{5(4)}\right)}
\end{aligned}
$$

Tabel 4. Hasil Pengujian Kesesuaian Model

\begin{tabular}{ccccccccc}
\hline \multirow{2}{*}{$\begin{array}{c}\text { Statistik } \\
\text { Uji }\end{array}$} & \multicolumn{2}{c}{ Hubungan 1 } & \multicolumn{2}{c}{ Hubungan 2 } & \multicolumn{2}{c}{ Hubungan 3 } & \multicolumn{2}{c}{ Hubungan 4 } \\
\cline { 2 - 8 } & Chi-square & p-value & Chi-square & p-value & Chi-square & p-value & Chi-square & p-value \\
\hline Pearson & 90.483 & 0.000 & 12.643 & 0.892 & 17.146 & 0.580 & 7.267 & 0.064 \\
Deviance & 52.820 & 0.016 & 11.725 & 0.925 & 15.388 & 0.698 & 7.421 & 0,060 \\
Keputusan & \multicolumn{2}{c}{ Terima Ho } & \multicolumn{2}{c}{ Terima Ho } & Terima Ho & Terima Ho \\
\hline
\end{tabular}

Berdasarkan model duga regresi logistik ordinal selanjutnya akan dilakukan uji untuk mengetahui apakah model duga sesuai atau tidak. Hipotesis yang akan diuji adalah

Ho: model sesuai

$\mathrm{H}_{1}$ : model belum sesuai

Ditinjau dari statistik uji Pearson dan Deviance pada Tabel 4 yang digunakan untuk hubungan struktural 1 yaitu variabel orang tua $\left(\mathrm{X}_{1}\right)$ dan dosen $\left(\mathrm{X}_{2}\right)$ terhadap pemahaman mahasiswa mengenai uang dan menabung $\left(\mathrm{Y}_{1}\right)$, diperoleh nilai $p$-value lebih kecil dari taraf siginikansi (0.01). Sehingga dapat disimpulkan bahwa model yang dihasilkan pada hubungan struktural 1 sudah sesuai. Berdasarkan statistik uji Pearson dan Deviance yang digunakan untuk hubungan struktural 2 yaitu variabel orang tua $\left(\mathrm{X}_{1}\right)$ dan dosen $\left(\mathrm{X}_{2}\right)$ terhadap variabel minat mahasiswa menabung $\left(\mathrm{Y}_{2}\right)$ diperoleh nilai $p$-value lebih besar dari taraf siginikansi (0.05). Sehingga dapat disimpulkan bahwa model yang dihasilkan pada hubungan struktural 2 sudah sesuai.

Berdasarkan statistik uji Pearson dan Deviance yang digunakan untuk hubungan struktural 3 yaitu variabel kebutuhan mahasiswa $\left(\mathrm{X}_{3}\right)$ dan program menabung kampus $\left(\mathrm{X}_{4}\right)$ terhadap 
variabel minat mahasiswa menabung $\left(\mathrm{Y}_{2}\right)$, diperoleh nilai p-value lebih besar dari taraf siginikansi (0.05). Sehingga dapat disimpulkan bahwa model yang dihasilkan pada hubungan struktural 3 sudah sesuai. Berdasarkan statistik uji Pearson dan Deviance yang digunakan untuk hubungan struktural 4 yaitu variabel pemahaman mahasiswa mengenai uang dan menabung ( $\left.\mathrm{Y}_{1}\right)$ terhadap variabel minat mahasiswa menabung $\left(\mathrm{Y}_{2}\right)$, diperoleh nilai $p$-value lebih besar dari taraf siginikansi (0.05). Sehingga dapat disimpulkan bahwa model yang dihasilkan pada hubungan struktural yaitu model ke empat sudah sesuai.

Tabel 5. Koefisien Determinasi $\left(\mathrm{R}^{2}\right)$ Setiap Hubungan

\begin{tabular}{|c|c|c|c|c|}
\hline $\begin{array}{c}\text { Koefisien } \\
\text { Determinasi }\end{array}$ & Hubungan 1 & Hubungan 2 & Hubungan 3 & Hubungan 4 \\
\hline $\mathrm{R}^{2}$ McFaden & $0.181(18.1 \%)$ & $0.071(7.1 \%)$ & $0.109(10.9 \%)$ & $0.027(2.7 \%)$ \\
\hline $\mathrm{R}_{\mathrm{m}}^{2}$ & \multicolumn{4}{|c|}{$0.341(34.1 \%)$} \\
\hline
\end{tabular}

Tabel 6. Perbandingan Pengaruh Langsung dan Tidak Langsung

\begin{tabular}{|c|c|c|c|c|c|c|c|}
\hline & & \multicolumn{3}{|c|}{$\mathrm{X}_{1}$ ( Pengaruh Langsung) } & \multicolumn{3}{|c|}{$\begin{array}{c}\mathrm{X}_{1} \text { ( Pengaruh Tidak } \\
\text { Langsung) }\end{array}$} \\
\hline & & $3(\mathrm{KS})$ & $4(S)$ & $5(\mathbf{S S})$ & $3(\mathrm{KS})$ & $4(S)$ & $5(\mathbf{S S})$ \\
\hline \multirow{3}{*}{$Y_{2}$} & $3(\mathrm{KS})$ & 1.0034 & 0.9385 & 1.0618 & 0.9917 & 1.0084 & 0.9999 \\
\hline & $4(S)$ & 0.8918 & 8.3586 & 0.1341 & 1.3220 & 0.7553 & 1.0014 \\
\hline & $5(\mathrm{SS})$ & 1.1174 & 0.1274 & 7.0210 & 0.7627 & 1.3129 & 0.9986 \\
\hline
\end{tabular}

Tabel 6 dapat dilihat bahwa nilai odds ratio pengaruh langsung dan pengaruh tidak langsung untuk pengaruh variabel orang tua terhadap motivasi menabung mahasiswa berbeda. Nilai odds ratio pengaruh langsung lebih tinggi dibandingkan nilai odds ratio pengaruh tidak langsung. Hal ini ditunjukkan dengan variabel pengaruh orang tua memberikan pengaruh langsung terhadap motivasi menabung mahasiswa sebesar 8.3586 kali dibandingkan orang tua yang tidak memberikan pengaruhnya. Sedangkan pengaruh tidak langsung orang tua terhadap motivasi menabung mahasiswa sebesar $1.3129 \mathrm{kali}$ dibandingkan orang tua yang tidak memberikan pengaruhnya.

Tabel 7. Perbandingan Pengaruh Langsung dan Tidak Langsung

\begin{tabular}{clcccccc}
\hline & \multicolumn{3}{c}{$\mathbf{X}_{2}$ (Pe ngaruh Langsung) } & \multicolumn{3}{c}{$\begin{array}{c}\text { X (Pengaruh Tidak } \\
\text { Langsung) }\end{array}$} \\
\cline { 3 - 8 } & & $\mathbf{3 ( K S )}$ & $\mathbf{4}(\mathbf{S})$ & $\mathbf{5}(\mathbf{S S})$ & $\mathbf{3 ( K S )}$ & $\mathbf{4}(\mathbf{S})$ & $\mathbf{5 ( S S )}$ \\
\hline \multirow{3}{*}{$\mathrm{Y}_{2}$} & $3(\mathrm{KS})$ & 1.0001 & 0.9953 & 1.0045 & 1.0006 & 0.9986 & 1.0007 \\
& $4(\mathrm{~S})$ & 0.9945 & 1.1702 & 0.8591 & 0.9802 & 1.0466 & 0.9746 \\
& $5(\mathrm{SS})$ & 1.0053 & 0.8585 & 1.1586 & 1.0195 & 0.9567 & 1.0251 \\
\hline
\end{tabular}

\section{KESIMPULAN DAN SARAN \\ KESIMPULAN}

Kesimpulan berdasarkan hasil penelitian yang dilakukan adalah

1. Variabel yang memberikan pengaruh langsung terhadap variabel $Y_{2}$ (motivasi mahasiswa menabung) adalah variabel $\mathrm{X}_{1}$ (Orang tua) dan $\mathrm{X}_{2}$ (Dosen). Pengaruh langsung variabel pengaruh orang tua terhadap motivasi menabung memiliki nilai odds ratio sebesar 8.3586 memberikan arti bahwa pengaruh secara langsung orang tua mempengaruhi motivasi menabung mahasiswa sebesar 8.3586 kali dibanding orang tua yang tidak memberikan pengaruhnya.

2. Pengaruh tidak langsung variabel pengaruh orang tua terhadap motivasi menabung mahasiswa melalui variabel pemahaman mahasiswa tentang uang dan menabung memiliki nilai odds ratio sebesar 1.3129 memberikan arti bahwa orang tua mengedukasi anaknya menabung akan memberikan pengaruh sebesar 1.3129 kali dibandingkan orang tua yang tidak mengedukasi anaknya. 
3. Variabel orang tua memberikan pengaruh yang signifikan terhadap variabel motivasi mahasiswa menabung.

\section{SARAN}

Saran berdasarkan penelitian yang dilakukan adalah

1. Untuk penelitian selanjutnya agar lebih berhatihati dalam membuat pertanyaan dalam kuisioner

2. Perlu pemgembangan menggunakan metode pendugaan parameter yang lain selain metode Maximum Likelihhod dengan iterasi Newton Raphson.

\section{DAFTAR PUSTAKA}

Agresti, A. (1990). Categorical Data Analyisis. John Willey \& Sons. New York

Amelia, Fitria. (2012). Motivasi Menabung Mahasiswa di Kampus Menengah Pertama Negeri 1 Kampar. Skripsi S1: Program Studi/Jurusan Pendidikan Ekonomi/ Tarbiyah dan Kedosenan. Universitas Islam Negeri Sultan Syarif Kasim Riau. Riau

Bank Indonesia. (2014). Laporan Keuangan Bank Indonesia. Jakarta. Bank Indonesia

Djamarah, Syaiful Bahri. (2002). Rahasia Sukses Belajar. Rineka Cipta. Jakarta

Ghozali, Imam. (2011). Aplikasi Analisis Multivariate dengan Program SPSS. Semarang. Badan Penerbit Universitas Diponegoro
Hair, J.F. (1995). Multivariate Data Analysis. Prentice Hall: New Jersey

Hasibuan. (2008). Dasar-dasar Perbankan. Bumi Aksara. Jakarta

Hosmer, D.W. and Lemeshow, S. (2000). Applied Logistik Regression. John Wiley \& Sons, New York.

Ritonga dan Yoga Firdaus. (2006). Ekonomi untuk SMA Kelas X. Phibeta Aneka Gama. Jakarta

Slameto. (2004). Belajar dan Faktor-Faktor yang Mempengaruhinya. Rineka Cipta. Jakarta

Sudja, Fadhilal Sudrajat. (2016). Analisis Minat Mahasiswa Menabung di Kampus (Studi kasus pada SMP Negeri I Garut Tahun Pelajaran 2016/2017). Skripsi S1: Prodi/ Jurusan Pendidikan Ekonomi /Pendidikan Ekonomi dan Bisnis. Bandung. Universutas Pendidikan Indonesia.

Sunyoto. (2011). Analisis Regresi untuk Uji Hipotesis. Yogjakarta. Caps

Tanzia, Ike dan Eka Herdiana. (2009). Analisis Jalur Faktor-Faktor yang Mempengaruhi Ketahanan Pangan Rumah Tangga di Kabupaten Lebak, Provinsi Banten. Jurnal Gizi dan Pangan, Vol 4, No 2. http://journal.ipb.ac.id/index.php/jgizipangan/ article/view/4527/3030. Tanggal akses 26 Maret 2020.

Wahana, Arwansa. (2014). Faktor-Faktor Yang Mempengaruhi Perilaku Mahamahasiswa Dalam Menabung. Skripsi S1: Fakultas/ Jurusan Ekonomika dan Bisnis / IESP. Semarang. Universitas Diponegoro. 